\title{
SOME DYNAMIC FEATURES OF DEPTH PERCEPTION
}

\author{
D. REGAN ${ }^{1}$ and K. I. BeVERLEY ${ }^{2}$ \\ Department of Communication, University of Keele, Staffordshire ST5 5BG, England
}

(Received 25 November 1971; in revised form 31 May 1973)

\section{INTRODUCTION}

THIS ARTICLE describes part of a study whose aim is to use the human brain's electrical responses to stereoscopic stimulation (REGAN and SPEKREUSE, 1970) as a "bridge" between psychophysical (human) and single-neuron (animal) studies of disparity processing.

The subjective illusion of depth can be generated by retinal disparity alone (WHEATSTONE, 1838,1852 ) even when there are no monocular cues to depth at all (JULESZ, 1960). In preliminary experiments (REGAN and SPEKREIJSE, 1970) the subject viewed a constant pattern of random squares (Julesz pattern) with one eye while the other eye viewed the same pattern the central area of which was rhythmically displaced from side to side. When the patterns viewed by the two eyes were binocularly fused the subject experienced a compelling illusion that the central part of the pattern was advancing and retreating in depth. We found that the distance through which the central portion of the pattern appeared to move in depth was strongly affected by the repetition frequency with which the retinal disparity of the central portion was alternated. For a constant excursion of retinal disparity the amplitude of the oscillation in depth grew progressively less as stimulus repetition frequency was increased beyond roughly 2 or $3 \mathrm{~Hz}$, so that at $5 \mathrm{~Hz}$ changes in perceived depth were very much smaller than for frequencies below $1 \mathrm{~Hz}$. Thus, high-frequency attenuation set in at a much lower frequency than for the perception of luminance flicker (beyond $10 \mathrm{~Hz}$, DE LANGE, 1957), or even for the perception of wavelength modulation (roughly $45 \mathrm{~Hz}$, REGAN and TYLER, 1971).

In this article we extend this observation and also describe how a subject's ability to utilize disparity cues in detecting a target's movement is affected by the frequency of the target's oscillation. We report psychophysical findings which bear on the question whether the dynamic characteristics of binocular depth perception differ for stimuli located in front of, behind and near the plane of fixation.

\section{METHODS}

The subject used both eyes to view a fixation plane defined by a random dot pattem which subtended a visual angle of $5^{\circ} \times 5^{\circ}$ at a viewing distance of $75 \mathrm{~cm}$. The luminance of the bright parts of the background was $110 \mathrm{~cd} / \mathrm{m}^{2}$. The dots in the fixation plane (whose purpose was to assist the subject to maintain steady convergence) occupied roughly 1 per cent of the background area and subtended some $1^{\prime}$.

The upper half (15' long) of the nonious line was seen by the left eye and the lower half by the right eye. When the two eyes converged correctly onto the fixation plane, the two halves of the nonious line were in register and appeared as a single vertical line. If convergence altered, the two halves separated.

When the subject viewed the stimulus with both eyes he saw two vertical black bars $\left(2^{\circ} \times 7^{\circ}\right)$ aligned vertically one degree to either side of the central nonious line. The left hand bar was always stationary. It

${ }^{1}$ Supported by the Medical Research Council.

2 Supported by the Science Research Council. 
could be adjusted so as to appear to stand out in depth either in front or behind the fixation plane and to remain permanently at this position. The right hand bar was not stationary, but appeared to oscillate in depth about a constant pre-set depth either in front of, behind or in the fixation plane. This was arranged as follows. The left eye viewed the pattern shown in Fig. 1(a). The patterns shown in Figs. 1(b and c) were superposed and viewed by the right eye. Then the bar shown in Fig. l(b) was set at some constant position so that it would fuse with the left hand bar of Fig. 1(a) so as to give the illusion of a single bar at a different depth to the dotted fixation plane. At the same time the bar of Fig. 1(c) was oscillated from side to side so that it would fuse with the right hand bar of Fig. I(a) to give the illusion of a second single bar oscillating in depth.

A slightly different arrangement was adopted for the experiments of Fig. 2 where the illusion that a single bar oscillated in depth was generated by oscillating from side to side both the right hand bar of Fig. 1(a) and the bar of Fig. 1(c). The amplitudes of oscillation of both bars was equal. Subjects viewed three kinds of stimuli in the experiments of Fig. 2. For both stereoscopic and binocular stimulation the left and right

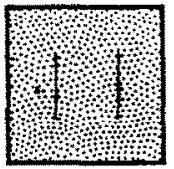

(a)

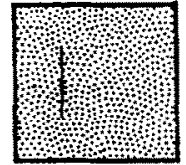

(b)

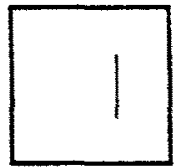

(c)

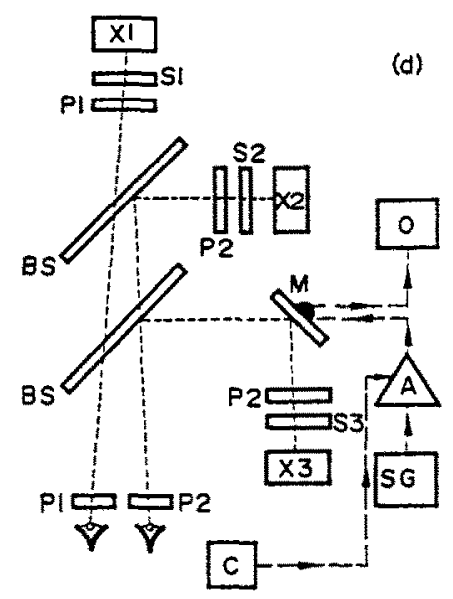

Fio. 1. (a) shows pattern seen by left eye. (b) and (c) show patterns seen by right eye. (d) schematic of apparatus: $\mathrm{X} 1, \mathrm{X} 2, \mathrm{X} 3$-fluorescent tube light sources; S1 -stimulus transparency (a); S2-stimulus transparency (b) for which the black bar is mounted separately on a micrometer drive so that its horizontal position can be altered relative to the dotted background. In this way the disparity of the left hand bar can be altered; S3-stimulus transparency (c); P1, P2-polaroids; BS-beam splitter; M-front surface mirror mounted on a pen motor. Rotation of the mirror deffects stimulus bar (c) and hence changes the right hand bar's disparity; SG-signal generator; A-amplifier to drive pen motor; $\mathrm{O}$-oscilloscope, measuring voltage across pen motor, hence deflection of stimulus bar (c); C-subject's control potentiometer.

retinal images oscillated through the same distances at $0.1 \mathrm{~Hz}$, but in the stereoscopic case they oscillated in antiphase whereas in the binocular case they oscillated inp hase. Thus, the only difference between stereoscopic and binocular stimulation was in the relative timing of the left and right retinal image movements. In the third stimulus condition (monocular) either the left or the right eye was occluded and the stimulus viewed by one eye alone.

The ways in which the disparities of the bars were controlled (and therefore the perceived depth altered) is shown in Fig. 1(d).

In the matched depth experiments of Figs. 5, 6 and 7 the left hand bar was adjusted to stand out either behind or in front of the fixation plane at some constant depth which could be varied up to $20^{\circ}$ of disparity. 

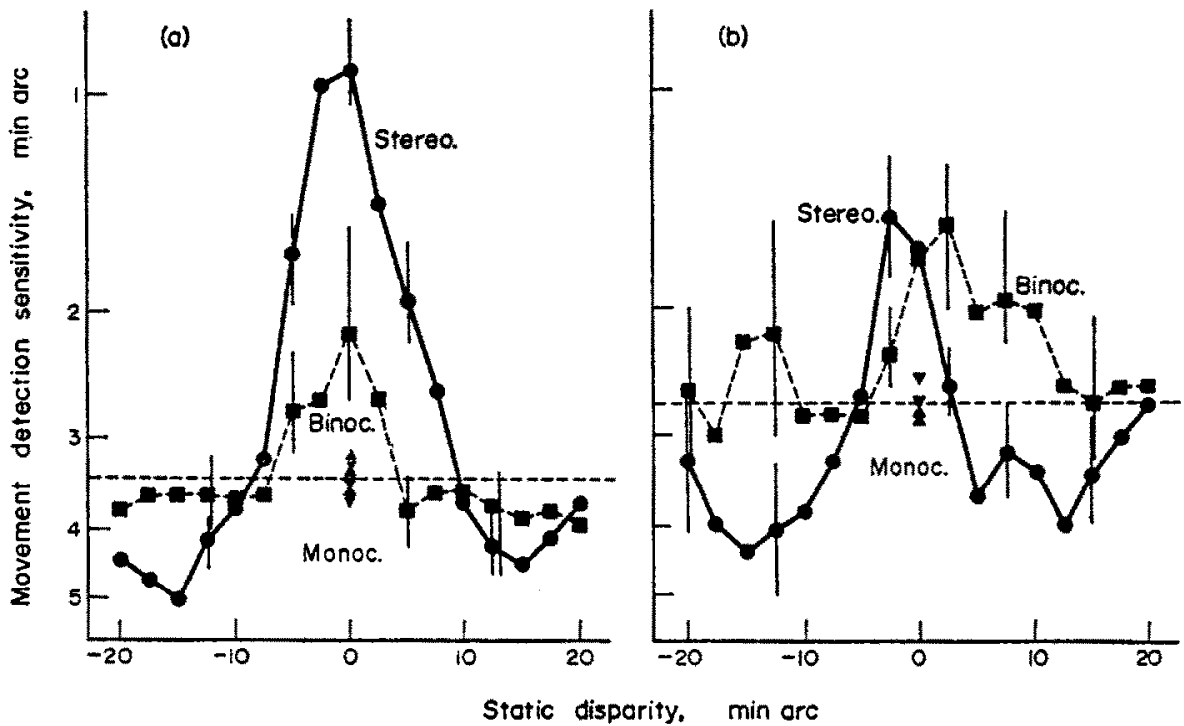

Fig. 2. The influence of disparity cues on sensitivity to movement. Ordinates are amplitudes of oscillation of either left or right eye's target when subject could just detect motion. Abscissae are mean disparities of stimuli. Zero disparity is in plane of fixation; positive (crossed) disparities are nearer than fixation plane and negative (uncrossed) disparities are further than fixation plane. In the stereoscopic case (continuous lines) the targets viewed by the left and right eyes oscillated in antiphase (always in opposite directions) so that disparity varied as well as retinal image position. In the binocular case (dotted lines) the targets oscillated inphase (always in the same direction) so that disparity was constant while retinal image position varied. For monocular stimulation either the right (upright triangles) or left (inverted triangles) eye was occluded. The horizontal dashed line is drawn through the mean monocular threshold. Oscillation frequency $0.1 \mathrm{~Hz}$. Each point is mean of five settings. The bars show the total range of settings. (a) is for subject $\mathrm{KB}$; (b) is for stereoanomalous subject JB.

The right hand bar was then centred on the fixation plane and oscillated in depth at some fixed frequency. The subject adjusted a potentiometer which altered the amplitude of the right hand bar's oscillation of retinal disparity, and hence the distance through which it appeared to oscillate backwards and forwards. The subject set the potentiometer so that the right hand bar's extreme excursion in depth just matched the apparent depth of the comparison bar on the left.

In the threshold experiments of Figs. 3 and 4 the right hand bar was set at some fixed retinal disparity so that it appeared to stand out in depth either in front of or behind the fixation plane or alternatively was in the fixation plane. The apparent depth of the bar was then oscillated about this mean position. The subject was instructed to alter the excursion of retinal disparity until he could just perceive an oscillation in depth. All subjects made at least five settings on each point both for "just able to see depth" and "just unable to see depth". This measurement was then repeated for a range of oscillation frequencies. We obtained similar results when we used the method of adjustments or the forced choice method. In most experiments, therefore, we used the method of adjustments since subjects preferred this technique. The experimenter was able to ensure that the position of the subjects' potentiometer gave no consistent clue to the retinal disparity of the stimulus.

In some threshold experiments the bar stimuli were replaced by a random dot stimulus. The dot stimulus subtended $5^{\circ}$. The retinal disparity of the central $2.5^{\circ}$ disc could be oscillated so that the central disc appeared to move in depth.

In the control experiments of Fig. 4 an opaque black bar was physically oscillated from side to side by a vibrator. This bar was seen by both eyes (binocular) or by one eye (monocular) superimposed to the right of the nonius line on the stimulus shown in Fig. 1(b). The stimuli of Figs. 1(a and c) were oceluded. The moving bar could be positioned $(+) 5^{\prime}$ in front of the fixation plane, $(-) 5^{\prime}$ behind the fixation plane, or very close to the fixation plane (less than $\mathrm{I}^{\prime}$ away). It should be emphasized that the stimuli seen by the right eye in all the experiments appeared identical. Only the left eye's stimuli differed. 
Four subjects were used of whom two were male and two female. All were given practice in the required psychophysical judgements before recordings were made. The subjects were allowed frequent rests during an experimental session.

\section{RESULTS}

\section{Threshold data}

Since changes in retinal disparity must be accompanied by movements of one or both retinal images there are two cues that a subject can use in detecting depth movements. One cue is movements of the retinal image(s) and the other cue is disparity changes that may accompany the retinal image movements. When stimulus movements are reduced to nearthreshold amplitudes it is very difficult to decide whether movement is in depth or sideways. Therefore, in threshold experiments our subjects did not attempt to distinguish between depth movement and sideways movement, but merely detected whether the target moved at all.

For stereoscopic stimulation, movement cues included disparity changes, but there were no disparity cues with binocular stimulation.

Influence of the stimulus location relative to the fixation plane. Sensitivity to stereoscopic stimuli [continuous line, Fig. 2(a)] was higher than sensitivity to binocular stimulation (dotted line) only in a narrow region around the plane of fixation. This region, which did not extend much more than $5^{\prime}-7 \cdot 5^{\prime}$ in front of or behind the plane of fixation, was symmetrical with respect to the plane (to within $2 \cdot 5^{\prime}$ ). The presence of this narrow region of high stereoscopic sensitivity was confirmed in a further two subjects. Subjects were not able to utilize disparity cues so as to enhance their sensitivity to movement when the stimulus was located more than $10^{\prime}$ from the fixation plane. On the contrary, sensitivity was then lower to stereoscopic stimulation than to binocular stimulation. Stereoscopic sensitivity could even fall below sensitivity to monocular stimulation (compare the horizontal straight line in Fig. 2(a) with the continuous line for static disparities between $+10^{\prime}$ to $+20^{\prime}$ and $-10^{\prime}$ to $-20^{\prime}$ ). In other words, subjective sensitivity to movement could be increased by occluding one eye while viewing a stereoscopic stimulus. ${ }^{3}$

Subject JB's stereoscopic curve was symmetrical about the fixation plane [Fig. 2(b)] although in other ways this subject differed from the other three (see below).

Effect of stimulus modulation frequency; frequencies above $1 \mathrm{~Hz}$. Figure 3 shows that when stimulus modulation frequency exceeded $1 \mathrm{~Hz}$ stereoscopic threshold was not affected by whether the stimulus was in the fixation plane, in front of the fixation plane (mean disparity $-5^{\prime}$ ) or behind the fixation plane (mean disparity $+5^{\prime}$ ). This held both for sinewave and squarewave stimulation. Furthermore, binocular and stereoscopic thresholds were also similar when stimulus frequency exceeded $1 \mathrm{~Hz}$ [Fig. 4(a)]. Finally, subjects

\footnotetext{
${ }^{3}$ This may relate to TYLER'S (1971) recent finding that sensitivity to stereoscopic depth movement is less than sensitivity to monocular movement. However, his control of fixation by means of a stationary fixation line rather than by using nonious lines did not give the precision necessary to detect the region within some $\pm 5^{\prime}$ of the fixation plane where we find sensitivity to stereoscopic movement to be markedly greater than sensitivity to monocular movement.

A second question concerns possible vergence tracking of stereoscopic stimuli in Tyler's experiment. Tyler (personal communication) states that in later experiments he controlled for possible vergence tracking within Panum's fusional region by using two stimulus bars whose simultaneous oscillations in depth were such that they always moved in opposite directions. When the oscillation frequency was less than $1 \mathrm{~Hz}$ he no longer found that stereoscopic sensitivity was lower than monocular sensitivity. However, we report here and elsewhere (REGAN and BEVERLEY, 1973) that it is only for stimulus frequencies below roughly $1 \mathrm{~Hz}$ that disparity cues affect movement sensitivity.
} 
reported that stereoscopic stimuli a little way above threshold gave only weak impressions of depth; stimulus oscillations seemed to be almost entirely sideways. For stimulus frequencies exceeding roughly $5 \mathrm{~Hz}$, subjective sensitivity fell off rapidly (not shown in figures). Results for the random dot stimulus were essentially similar. All this suggested that threshold curves above $1 \mathrm{~Hz}$ did not describe a dynamic property of depth perception.

The implication here was that subjects were unable to utilize disparity cues to help them detect movement when the target's oscillation frequency exceeded $1 \mathrm{~Hz}^{4}$

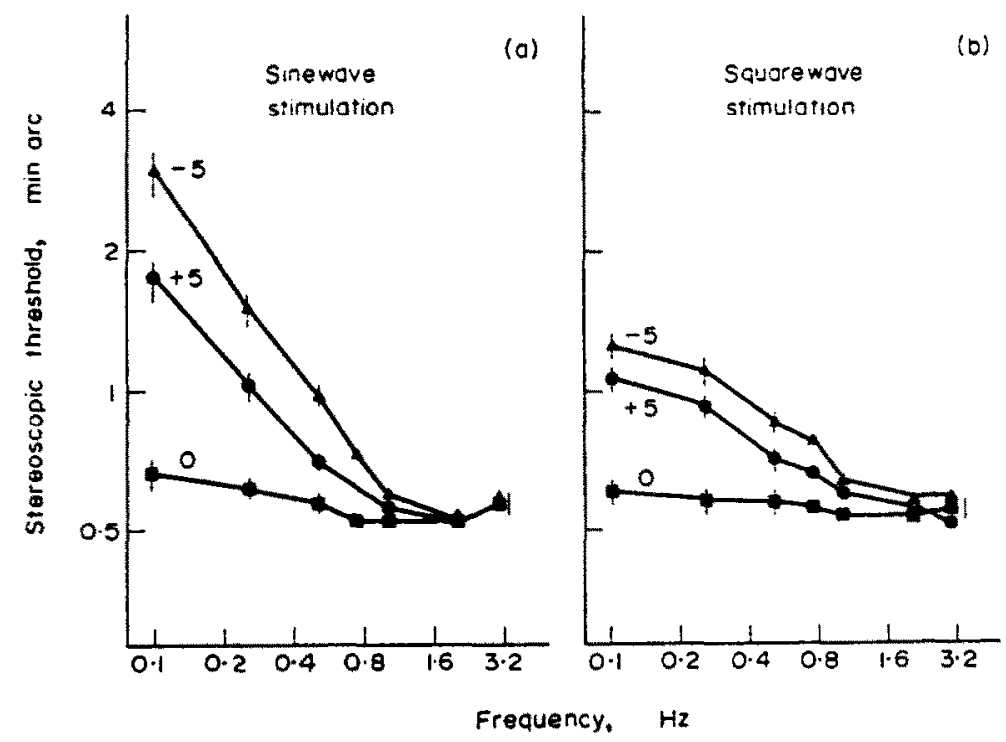

Fig. 3. Movement threshold plotted vs stimulus frequency for three mean disparities of +5 (crossed), 0 and $-5^{\prime}$ (uncrossed). (a) Sinewave stimulation; (b) squarewave stimulation. Vertical lines show \pm 1 standard deviation.

Effect of stimulus modulation frequency; stereoscopic sensitivity for frequencies below $1 \mathrm{~Hz}$. Figure 3(a) shows plots of threshold vs stimulus modulation frequency for three values of mean disparity $\left(+5^{\prime}, 0\right.$ and $\left.-5^{\prime}\right)$.

When retinal disparity was modulated sinusoidally there was strong low-frequency attenuation below roughly $1 \mathrm{~Hz}$. The slope of the curve was steeper for a mean disparity $-5^{\prime}$ (uncrossed) than for $+5^{\prime}$ (crossed) and was least for zero mean disparity. ${ }^{5}$

\footnotetext{
4 Our data relate only to the detection of movement, and leave open the possibility that our subjects could discriminate between stereoscopic and binocular stimuli at threshold even though their detectabilities were identical.

${ }^{3}$ Suppose both eyes are fixated on one index finger held vertically while the second index finger, also pointing vertically, is slowly moved from near the first index finger away from the eyes. At some point the second finger will appear to double. Each of these double images is often called a "half image". If the right eye is suddenly closed the right half-image will disappear. The images are said to be uncrossed disparate because the image that disappears is on the side of the closed eye. If now both eyes are fixated on one index finger while the second index finger, starting from a position near the fixation point, is slowly moved towards the eyes again there will come a point where the second finger appears double. If the right eye is now closed, the left half image disappears. The images are said to be crossed disparate because the image that disappears is on the opposite side to the closed eye (OGLE, 1950, pp. 40-41).
} 
Plots for squarewave modulation of disparity [Fig. 3(b)] differed from the sinewave plots. The steepness of the low-frequency attenuations were markedly reduced both for crossed and uncrossed disparities, and the difference between the $+5^{\prime}$ and $-5^{\prime}$ curves was no longer significant. On the other hand sinewave and squarewave curves were similar for zero mean disparity.

At first sight these findings suggest that sensitivity to changes in disparity depended on mean disparity. However, since we had found that disparity changes were ineffective cues when stimulus frequency exceeded $1 \mathrm{~Hz}$, it was clearly unsafe to assume that they were the predominant cue to movement at lower frequencies. Accordingly we carried out control experiments in which the stimuli were retinal image movements unaccompanied by changes in retinal disparity.
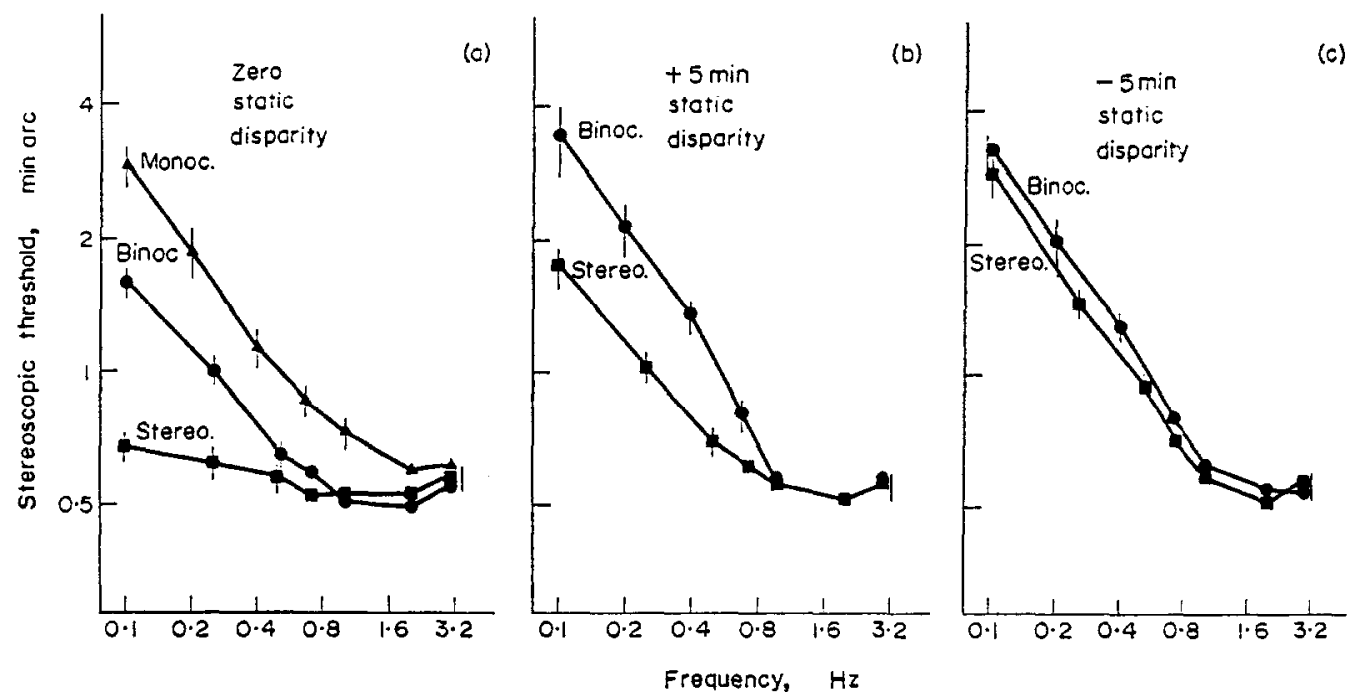

FIG. 4. Movement threshold vs stimulus frequency control experiments; sinewave stimulation. The curve through the triangles shows monocular data; the right eye viewing Fig. 1, (b) and (c), the left eye either occluded, or viewing a pattern which produced retinal rivalry. The circles are binocular thresholds. The squares show stereoscopic thresholds replotted from Fig. 3(a). (a) zero static disparity; (b) $+5^{\prime}$ static disparity (crossed); (c) $-5^{\prime}$ static disparity (uncrossed). Vertical lines show \pm 1 standard deviation.

In one such control experiment we used binocular stimulation. The only difference between binocular and stereoscopic stimuli was that binocular stimuli were unaccompanied by disparity changes. The surprising result of this experiment was that the binocular thresholds depended on whether the stimulus was located in the fixation plane or slightly off the fixation plane (at $\pm 5^{\prime}$ mean disparity, Fig. 4). However, there were marked residual differences between the stereoscopic plots and the binocular control plots. These included (a) the $+5^{\prime}$ and $-5^{\prime}$ curves did not differ for binocular stimuli as they did for stereoscopic stimuli, and (b) the flattening of the zero-disparity curve was greater for the stereoscopic curve than for the binocular control.

Thus, these findings of differences between binocular and stereo thresholds indicated that subjects were indeed able to utilize disparity changes as a cue to movement when stimulus oscillation frequency was less than $1 \mathrm{~Hz}$. 
In a second control experiment stimulation was monocular. In some cases the left eye was occluded and in other cases the left eye viewed a pattern that was uncorrelated with the pattern viewed by the right eye (though both eyes continued to view the same background of random dots). As expected, retinal rivalry usually occurred when viewing uncorrelated patterns. Settings could be made only during the periods when the eye stimulated by the moving stimulus (the right eye) could see the stimulus. Recordings were made only for zero mean disparity, since for our monocular situations the depth of field of the subject's eye would eliminate any effective differences between the locations of the oscillating bar.

The two monocular situations gave similar results. Thresholds were independent of the static stimuli (left eye's) so long as no oscillation in depth could be seen [Fig. 4(a)]. Monocular and binocular curves were similar for static disparities of $+5^{\prime}$ and $-5^{\prime}$. However, for zero static disparity binocular thresholds were lower than monocular thresholds provided that stimulus frequency did not exceed $3-4 \mathrm{~Hz}$.

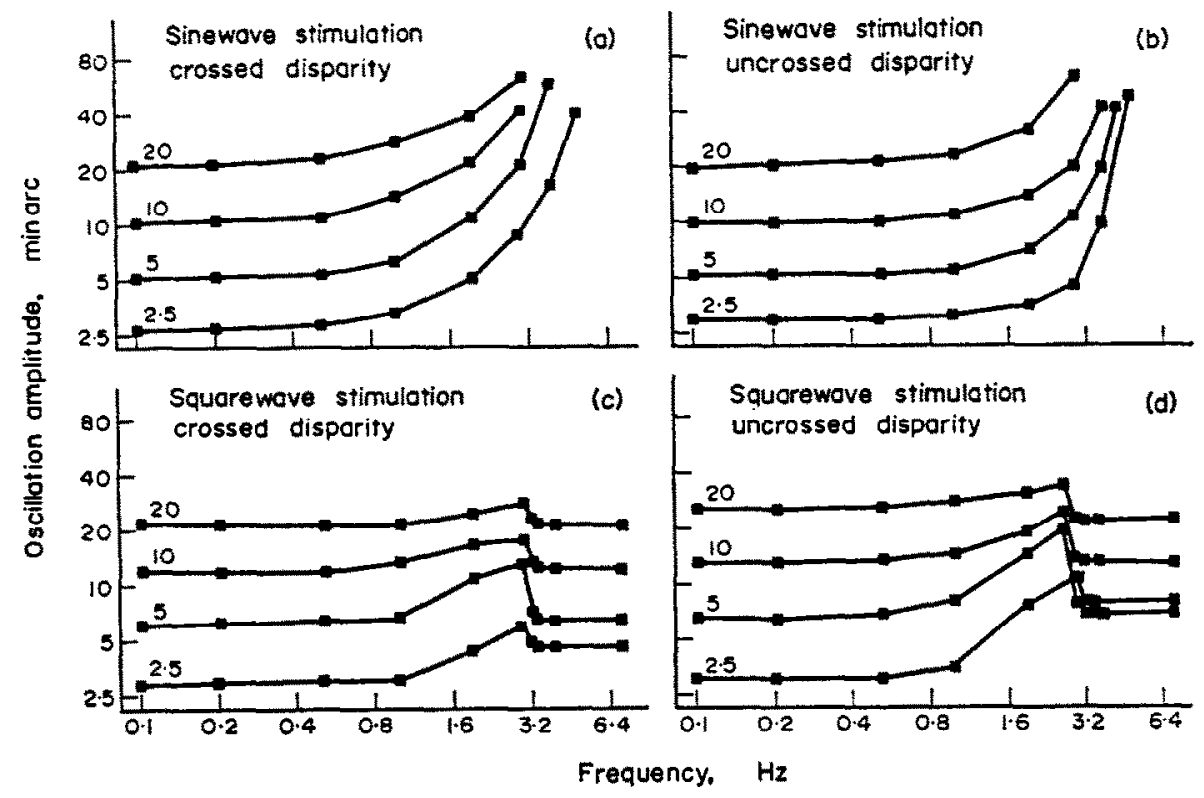

FIG. 5. Suprathreshold (matched depth) data. Depth sensitivity vs stimulus frequency for crossed and uncrossed disparities. The numbers on the curves give the static disparity (in minutes of arc) of the comparison bar to which the oscillation amplitude was matched. (a) Sinewave stimulation, crossed disparity; (b) sinewave stimulation, uncrossed disparity; (c) squarewave stimulation, crossed disparity; (d) squarewave stimulation, uncrossed disparity. Subject $\mathrm{KB}$.

\section{Suprathreshold data}

Figures $5(\mathrm{a}$ and $\mathrm{b})$ show that the shapes of the matched depth curves were quite different from the shapes of the threshold curves of Fig. 2(a). In contrast with the threshold curves, none of the suprathreshold curves showed low-frequency attenuation. ${ }^{6}$ In the sinewave suprathreshold curves, high-frequency attenuation was strong over the whole range of conditions investigated (i.e. depths equivalent to static disparities ranging from $+2 \cdot 5^{\prime}$ to

\footnotetext{
${ }^{6}$ Richaros (1972) finds low-frequency attenuation for suprathreshold curves (sinusoidal modulation), but only for disparities exceeding $30^{\prime}$. Our largest disparity was $20^{\prime}$,
} 
$+20^{\prime}$ and $-2 \cdot 5^{\prime}$ to $-20^{\prime}$ ). In contrast the suprathreshold curves for squarewave modulations of disparity were flat with a slight peaking near $3 \mathrm{~Hz}$ and then an abrupt increase in sensitivity (which is smoothed out in the averaged results of Fig. 5(c) since the breakaway point varied a little from run to run and there was also some hysteresis).

For frequencies below the breakaway point suprathreshold stimuli looked like a bar which oscillated in depth. Above the breakaway point the stimulus appeared quite different. It then looked like two stationary bars at different depths. ${ }^{7}$ The breakaway frequency varied from subject to subject. However, the correlation between the rise in sensitivity and the "stationary double-bar illusion" held for all subjects.

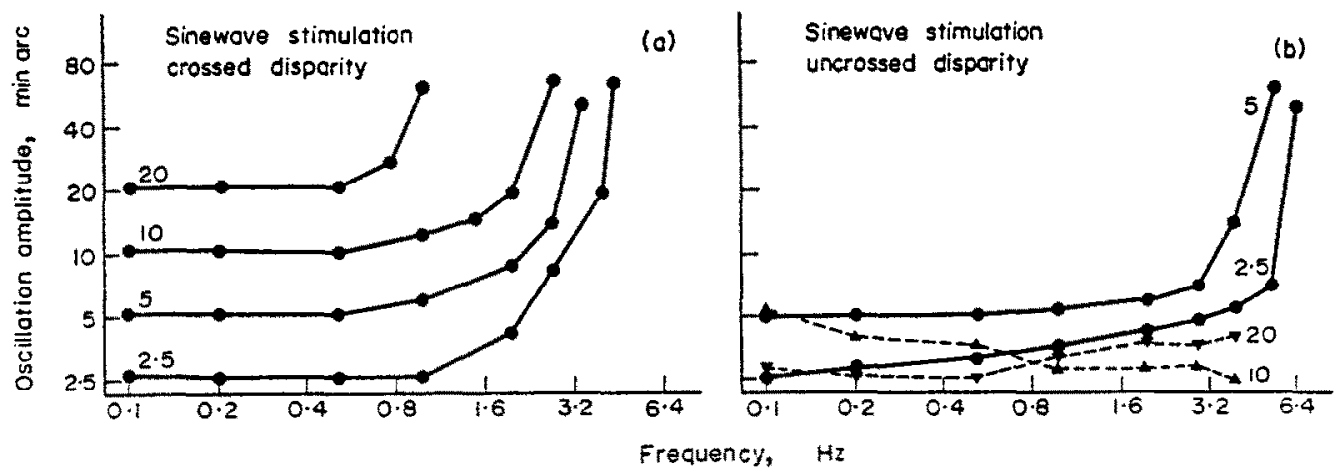

FiG. 6. As Fig. 5 except for different subject (JB)

Suprathreshold curves similar to those of Figs. $5(\mathrm{a}$ and $\mathrm{b})$ were obtained from all subjects except one. The results for this subject (JB) are shown in Figs. 6(a and b). Subject JB's matched depth data indicated that she did not see a corresponding increase of depth when stimulus disparities were increased beyond $-5^{\prime}$ (uncrossed), and this indeed was what she reported in words. For all other disparities, however, her results were similar to the other subjects' [cf. Figs. 5( $\mathrm{a}$ and $\mathrm{b})$ with Figs. $6(\mathrm{a}$ and $\mathrm{b})$ ].

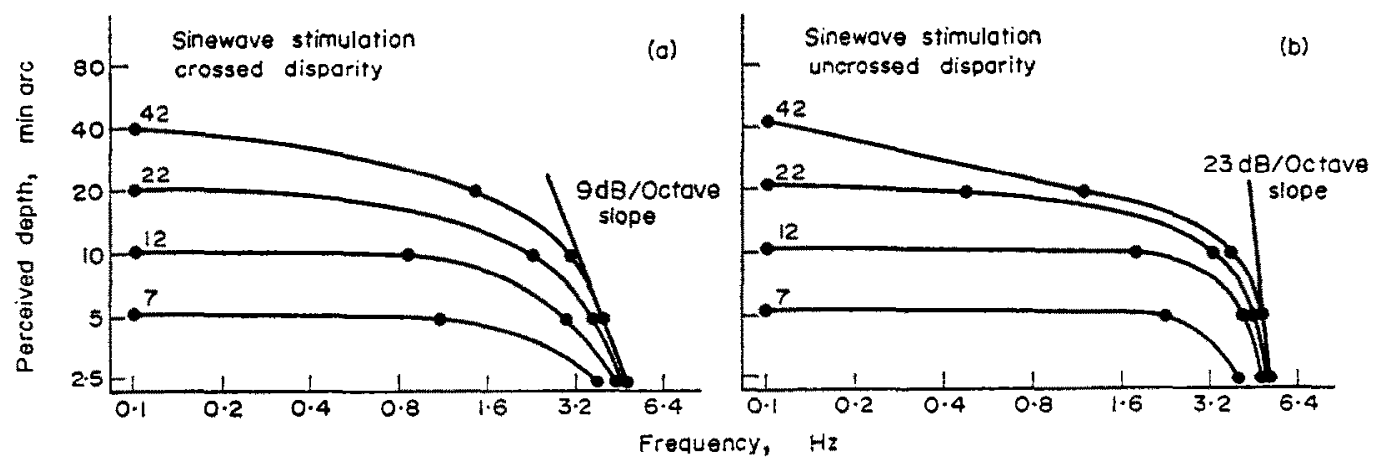

FrG. 7. Matched depth vs stimulation frequency for sinewave stimulation, for crossed and uncrossed disparities. The points are derived from curves similar to those shown in Figs. 5 and 6 . The asymptotic slopes of the curves for crossed and uncrossed disparities are shown. The numbers on the curves refer to the matched oscillation amplitude of the moving bar (in minutes of arc)

7 This effect can be regarded as an illusion of apparent movement in depth, analogous to the well-known illusion of apparent sideways movement. The illusion fails above the breakaway frequency. 
Data such as that of Figs. 5(a and b) are replotted in Figs. 7(a and b) in such a way as to emphasize the differences between the suprathreshold curves for crossed and uncrossed disparities. Each of the curves in plots such as $5(\mathrm{a})$ are transformed into a horizontal set of points in plots such as Fig. 7(a).

Figures 7(a and b) show how the apparent depth generated by a constant sinewave oscillation of disparity varied as a function of oscillation frequency. For all subjects the high-frequency attenuation of these curves increased more rapidly for uncrossed than for crossed disparities as stimulus frequency was increased; the difference in slopes could be as great as 2.5:1 at $42^{\prime}$ modulation amplitude [Figs. 7( $a$ and $\left.b\right)$ ]. The absolute values of the uncrossed and crossed high-frequency slope for plots such as those of Figs. 7( $a$ and $b$ ) were 18 and 15 (for the principal subject KB), 23 and 9,19 and 10 (all slopes in $\mathrm{dB} /$ octave). Our anomalous subject JB had a slope of $13.2 \mathrm{~dB}$ /octave for crossed disparities, but no slope could be obtained for uncrossed disparities.

\section{Accuracy of fixation}

\section{DISCUSSION}

First it is necessary to establish the accuracy of the fixation plane relative to the stimulus plane. Throughout these experiments we used nonious lines to monitor both fixation and also vergence tracking. We could detect a misalignment of roughly half the nonious lines' width; this corresponded to $0 \cdot 5^{\prime}$. A second argument that convergence was constant even when disparity was varying is that the "stereo" curves of Fig. 2 are centered on zero disparity (to within $2 \cdot 5^{\prime}$ ).

\section{Utilization of disparity cues in movement detection}

We find that there are circumstances where a subject's ability to detect the oscillations of a target is more sensitice when motion is accompanied by changes in retinal disparity than when it is not. This suggests that one would then see movement in depth more easily than sideways motion. However, this is only true provided that the target is very close to the plane of fixation (within $5^{\prime}-7 \cdot 5^{\prime}$ ) and that the stimulus frequency is less than $1 \mathrm{~Hz}$ at most. In contrast, disparity cues seem to reduce motion sensitivity when the target lies between $10^{\prime}$ and $20^{\prime}$ from the fixation plane. Thus for targets more than $10^{\prime}$ away from the fixation plane, our results suggest that movement in depth is more difficult to see than sideways movement. However, all this holds only when the target's frequency of oscillation is less than $1 \mathrm{~Hz}$. For oscillation frequencies above $1 \mathrm{~Hz}$, disparity changes do not seem to affect a subject's ability to detect movement.

The threshold dynamic characteristics of neural mechanisms that process disparity information cannot, of course, be obtained from our stereoscopic and binocular data by simple subtraction, since this would involve an (unproved) assumption of linearity. The confounding of disparity and movement cues seems inherent to our present method, though this confusion can be avoided (REGAN and BeVERLEY, 1973). At this time little more can be deduced by comparing Figs. 3(a) and 4(a, $b$ and $c)$ than that disparity cues have different effects on movement sensitivity for crossed, zero and uncrossed disparities.

\section{Effect of stimulus location on the processing of disparity information}

We find that sensitivity vs frequency curves for stereoscopic depth perception are different for crossed and uncrossed disparities. This finding holds for both threshold and suprathreshold stimulation and is consistent with RICHARDs' $(1970,1971)$ suggestion that crossed 
and uncrossed disparity detectors are organized into separate pools. In addition the threshold data of Figs. 2 and 3 are consistent with RICHARDs' $(1970,1971)$ hypothesis that disparity information is handled differently for stimuli near the plane of fixation than for stimuli located off the fixation plane (for technical reasons we did not make suprathreshold measurements in the fixation plane).

\title{
Anomalous binocular depth perception (stereoblindness)
}

An error in convergence would seem the most obvious explanation for subject JB's failure of depth perception for uncrossed disparities beyond $5^{\prime}$ coupled with her retention of depth perception for crossed disparities. In order to account for Fig. 6(b) a convergence error of $15^{\prime}$ (i.e. $20^{\prime}-5^{\prime}$ ) would be required. However, the symmetry of the "stereo" curve of Fig. 2(b) is evidence that any convergence error did not exceed $2 \cdot 5^{\prime}$, so that such errors cannot explain this subject's anomaly.

RicHARDS $(1970,1971)$ reported the existence of anomalies of binocular depth perception that he attributed to the functional absence of one or more of his three hypothetical pools of disparity detectors. In Richards' terms, subject JB's results could be explained as a selective loss of the pool of uncrossed disparity detectors.

The finding that subject JB showed no suprathreshold nor threshold anomaly for uncrossed disparities of $2 \cdot 5^{\prime}$ or $5^{\prime}$ suggests sparing of disparity detectors close to the fixation plane consistent with RICHARDS (1971) suggestion that disparity detectors near the fixation plane form a separate pool.

\section{REFERENCES}

De LANGe, H. (1957). Attenuation characteristics and phase shift characteristics of human fovea-cortex systems in relation to flicker-fusion phenomena. Thesis, Delft.

JuLESZ, B. (1960). Binocular depth perception of computer-generated patterns. Bell Syst. tech. J. 39, 11251162.

OGLE, K. N. (1950). Researches in Binocular Vision, p. 349, Hafner, New York.

REGAN, D. and SPEKREISSE, H. (1970). Electrophysiological correlate of binocular depth perception in man. Nature, Lond. 225, 92-94.

REgan, D. and TyLer, C. W. (1971). Some dynamic features of colour vision. Vision Res. 11, 1307-1324.

REGAN, D. and BEvERLEY, K. I. (1973). The dissociation of sideways movements from movements in depth: psychophysics. Vision Res. (in press).

RICHARDS, W. (1970). Stereopsis and stereoblindness. Exp. Brain Res. 10, 380-388.

Richards, W. (1971). Anomalous stereoscopic depth perception. J. opt. Soc. Am. 61, 410-414.

RICHARDS, W. (1972). Response functions for sine- and square-wave modulations of disparity. J. opt. Soc. Am. 62, 907-911.

TYLER, C. W. (1971). Stereoscopic depth movement: two eyes less sensitive than one. Science, N.Y. 174, 958-961.

WheAtstone, C. (1838). Contributions to the physiology of vision-I. Phil. Trans. R. Soc. 13, 371-374.

Wheatstone, C. (1852). Contributions to the physiology of vision-II. Phil. Trans. R. Soc. 142, (II), 1-18.

\begin{abstract}
Disparity cues affect a subject's ability to detect movement only when stimulus oscillation frquency is less than $1 \mathrm{~Hz}$. Disparity cues then increase sensitivity for targets close to the fixation plane (within $7 \cdot 5^{\prime}$ ), but decrease sensitivity for targets whose disparities are greater. Binocular sensitivity to sideways movement is higher for targets in the fixation plane than for targets with finite disparities. The effect of frequency upon depth sensitivity is different for crossed, uncrossed and zero disparities. Suprathreshold depth sensitivity has a steeper high-frequency attenuation for uncrossed than for crossed disparities. One "stereoanomalous" subject could see depth for crossed disparities but gave no depth responses at all for uncrossed disparities.
\end{abstract}


Résumé-Les indications de disparité n'affectent la capacité de détection de mouvement que si la fréquence d'oscillation du stimulus est moindre que $1 \mathrm{~Hz}$. Les indications de disparité augmentent alors la sensibilité pour des cibles proches du plan de fixation (à moins de $7,5^{\circ}$ ) mais diminuent la sensibilité pour des cibles de disparités plus grandes. La sensibilité binoculaire à des mouvements de côté est plus grande pour les cibles dans le plan de fixation que pour des cibles à disparités finies. L'effet de la fréquence sur la sensibilité à la profondeur diffère selon que la disparité est homonyme, croisée ou nulle. La sensibilité supraliminale à la profondeur a une atténuation plus raide en haute fréquence pour la disparité homonyme que pour la croisée. Sur un sujet "stéréoanomal" la profondeur était perçue en disparité croisée, mais il n'y avait pas du tout de réponse de profondeur en disparité homonyme.

Zusammenfassung-Disparationsmarkierungen beeinflussen die Fähigkeit einer Versuchsperson, eine Bewegung zu entdecken, nur dann, wenn die Oszillationsfrequenz des Testreizes kleiner als $1 \mathrm{~Hz}$ ist. Disparationsmarkierungen erhöhen dann die Empfindlichkeit für Testreize nahe der Fixationsebene (innerhalb 7,5'), vermindern sie dagegen für Tests, deren Disparationen grösser sind. Die binokulare Empfindlichkeit für die Seitwărtsbewegung ist für Tests in der Fixationsebene grösser als für Tests mit endlichen Disparationen. Der Einfluss der Frequenz auf die Tiefenwahrnehmung ist für gekreuzte, für ungekreuzte und für Nulldisparationen verschieden. Eine überschwellige Tiefenempfindung fällt für ungekreuzte Disparationen zu hohen Frequenzen hin steiler ab als für gekreuzte Disparationen. Eine "stereoanomale" Versuchsperson konnte bei gekreuzten Disparationen Tiefe wahrnehmen, nicht jedoch bei ungekreuzten Disparationen.

Резюме-Ситналы диспаратности влияют на способност в человека $\mathbf{k}$ обнаружению движения только в том случае, если частота осцилляцић стимула менее $1 \mathrm{ru}$. В этом сигналы диспаратности увеличивают чувствителъность к объектам находяшимся близко к точке фиксации (в пределах 7,5 мин), но они уменьаюит чувствительность к объектам диспаратность которыг больте. Бинокулярная чувствительность к боковым движениям выше для объектов находяшихся в точке фиксации по сравнению с объектами имеющиму определенную диспаратность. Влияние частоты на порог восприятия глубины различно для перекрестных, неперекрешиваюшихся и нулевых диспарапий. Сверхпороговая глубинная чувствительность имеет более крутое падение для высоких частот при неперекрешиваюшихся дпспарациях, чем при перекрестньх. Один ,,стереоаномальныи,, субъект мог видеть глубнну прн перекрешенных диспарациях, во не реагвровал на изменения глубины при всех неперехрещенных диспарациях. 